\title{
NBSIR 79-1934
}

\section{Proof Testing of Ceramics: I. Experiment}

\author{
J. E. Ritter, Jr. and P. B. Oates
}

Mechanical Engineering Department University of Massachusetts

Amherst, MA 01003

E. R. Fuller, Jr. and S. M. Wiederhorn

National Bureau of Standards

Fracture and Deformation Division National Measurement Laboratory

Center for Materials Science

National Bureau of Standards

December 1979

Prepared for

Department of Energy

Fossil Fuel Utilization Division

Washington, D.C. 



\title{
PROOF TESTING OF CERAMICS:
}

\section{EXPERIMENT}

\author{
J. E. Ritter, Jr. and P. B. Oates
}

Mechanical Engineering Department

University of Massachusetts

Amherst, MA 01003

E. R. Fuller, Jr. and S. M. Wiederhorn

National Bureau of Standards

Fracture and Deformation Division

National Measurement Laboratory

Center for Materials Science

National Bureau of Standards

December 1979

\section{Prepared for}

Department of Energy

Fossil Fuel Utilization Division

Washington, D.C.

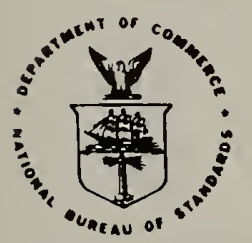

\section{U.S. DEPARTMENT OF COMMERCE}

\section{Luther H. Hodges, Jr., Under Secretary}

Jordan J. Baruch, Assistant Secretary for Science and Technology

NATIONAL BUREAU OF STANDARDS, Ernest Ambler, Director 



\title{
PROOF TESTING OF CERAMICS: I. EXPERIMENT
}

\author{
J.E. Ritter, Jr. and P.B. Oates \\ Mechanical Engineering Department \\ University of Massachusetts \\ Amherst, MA. 01003 \\ E.R. Fuller, Jr. and S.M. Wiederhorn \\ National Bureau of Standards \\ Washington, D.C. 20234
}

\begin{abstract}
The effectiveness of proof testing as a method of improving component reliability was studied by comparing the inert strength distributions of soda-lime-silicate glass before and after proof testing. The effects of unloading rate from the proof stress, hold time at the proof stress, and proof-test environment were examined. The results indicate that the proof test must be conducted with rapid unloading rates and good environmental control to be effective. The theoretical implications of these results are discussed.
\end{abstract}




\section{INTRODUCTION}

Proof testing is one means used to assure the mechanical reliability of structural ceramics. In proof testing, ceramic components are subjected to stresses that are greater than those expected in service in order to break the weak components and thus truncate the low end of the strength distribution. In this manner, weak components are eliminated before they can be placed in service. Proof testing has been applied to spacecraft windows, ${ }^{1,2}$ electrical porcelain insulators, ${ }^{3}$ and vitrified grinding wheels. 4

Wiederhorn, Evans, and Fuller ${ }^{5-7}$ have provided a mathematical foundation for the selection of the proof-test stress and the establishment of proof-test conditions. Their analysis is based on the assumption that failure of ceramics occurs from the growth of preexisting flaws. By characterizing this crack growth and coupling crack growth parameters with proof testing, they derived the strength after proof testing assuming flaw growth during the proof-stress, load-unload cycle. The resulting theory indicates that crack growth must be minimized to have effective proof testing. This can be achieved by having rapid unloading from the proof stress and good environmental control during the proof test.

In support of the proof-test theory, Ritter ${ }^{8}$ has shown recently for soda-lime silicate glass after proof testing that the inert strength distribution and failure time under static stress agree with that predicted from theory. Aside from this study, there has been no extensive experimental confirmation of proof-test theory. The purpose of the present study, therefore, was to conduct a detailed study of the proof-test technique and to assess the 
validity of the theory in predicting the strength after proof testing. In particular, the effectiveness of proof testing and the applicability of proof-test theory was determined by comparing the inert strength distributions of soda-lime silicate glass before and after proof testing over a range of proof-test conditions. The major proof test variables were unloading rate from the proof stress and the proof-test environment. Soda-lime-silicate glass was chosen as the model material for this study because it is readily available and because its subcritical crack behavior is well characterized.

\section{EXPERIMENTAL PROCEDURE}

All specimens used in this study were soda-lime-silicate glass, microscope slides ${ }^{+}(7.62 \times 2.54 \times 0.10 \mathrm{~cm})$. The slides were annealed at $500^{\circ} \mathrm{C}$ for $1 \mathrm{~h}$, furnaced cooled, and then abraded in the center with a standard blast of No. 240 SiC grit. After abrasion, the samples were aged for $24 \mathrm{~h}$ in distilled water to normalize their strength and then stored in a desiccator prior to testing. Over 2000 samples were prepared in this manner and they were randomly selected for testing.

The inert strength measurements before and after proof testing were made in liquid nitrogen using four point bending. The bending apparatus had inner and outer supports of 2.54 and $5.08 \mathrm{~cm}$., respectively. A11 strength testing was done on a universal testing machine ${ }^{\dagger}$ using a constant crosshead speed of $0.2 \mathrm{~cm} / \mathrm{min}$, corresponding to a stressing rate of $5.29 \mathrm{MPa} / \mathrm{s}$. The initial inert strength distribution was determined from 79 samples while the after-proof, strength distributions were determined from about 30 samples.

\footnotetext{
${ }^{+}$Corning No. 2947

tInstron Corp., Canton, MA.
} 
The bend apparatus was also used for proof testing. The samples were loaded up to the proof stress at a stressing rate of $5.29 \mathrm{MPa} / \mathrm{s}$ and then unloaded at various rates $(132.33,5.29$, and $1.32 \mathrm{MPa} / \mathrm{s})$. The time at the proof stress varied from momentary (less than $0.5 \mathrm{~s}$ ) to $60 \mathrm{~s}$. The proof test environments were liquid nitrogen, dry nitrogen gas (about $5 \%$ Relative Humidity), ambient air (55-65\% Relative Humidity) and water. The last three test environments were at room temperature, about $23^{\circ} \mathrm{C}$. Groups of 50 samples were proof tested for each proof-test condition and proof-test stresses were chosen to break approximately $40 \%$ of a set of test specimens, leaving about 30 samples for the determination of the inert strength distribution after proof testing.

\section{RESULTS AND DISCUSSION}

The strength after proof testing has been derived for 3 conditions: $:^{5-7}$ no flaw growth during proof testing, flaw growth up to unloading, and flaw growth during the entire proof-stress cycle. If no flaw growth occurs during the proof test, then the inert strength for a given specimen before and after proof testing are equal; however because the weak samples have been eliminated from the initial distribution, the cumulative failure probability after proof testing $\left(F_{a}\right)$ will have changed: ${ }^{5}$

$$
F_{a}=\frac{F-F_{p}}{1-F_{p}}
$$

where $F$ is the cumulative failure probability before proof testing and $F_{p}$ is the cumulative failure probability of the proof test. *

Assuming that a single power law relationship exists between subcritical crack velocity and the stress intensity factor,

${ }^{*} F$ is obtained by ordering a set of strength data. $F$ is given by $r /(N+1)$ where $N$ is the total number of datum points and $r$ is the position of each point in the ordered set. $r=1$ for the lowest strength, $r=2$ for the second lowest and so forth. 


$$
V=A K_{I}^{n}
$$

where $A$ and $n$ are constants for a given material and test environment, the inert strength after proof testing $\left(S_{f}\right)$ can be derived accounting for crack growth during the proof-stress cycle. Considering crack growth up to unloading but not during unloading, the $S_{f}$ distribution is given by: ${ }^{5,6}$

$\left(\frac{S_{f}}{S_{0}}\right)^{n-2}=\left(\ln \frac{1}{1-F_{a}}+\ln \frac{1}{1-F_{p}}\right)^{\frac{n-2}{m}}-\left(\ln \frac{1}{1-F_{p}}\right)^{\frac{n-2}{m}}+\left(\frac{\sigma_{p}}{S_{0}}\right)^{n-2}$

where $\mathrm{n}$ is the crack propagation parameter appropriate for the proof-test environment, $\sigma_{p}$ is the proof stress, and $m$ and $S_{0}$ are the Weibull shape and scale parameters, respectively, of the initial inert strangth distribution. If flaw growth occurs during the entire proof stress cycle, the $S_{f}$ distribution is now: 6

$$
\left(\frac{S_{f}}{S_{0}}\right)^{n-2}=\left(\ln \frac{1}{T-F_{a}}+\ln \frac{1}{1-F_{p}}\right)^{\frac{n-2}{m}}-\left(\ln \frac{1}{1-F_{p}}\right)^{\frac{n-2}{m}}
$$

For purposes of identification in the following discussion, the various predicted $S_{f}$ distributions will be labelled:

Type I, based on Eq. (1) for no flaw growth.

Type II, based on Eq. (3) for no flaw growth on unloading.

Type III, based on Eq. (4) for flaw growth during entire proof stress cycle.

For all three types of distributions it can be shown that $S_{f}$ is greater than the initial strength at all levels of failure probability, provided $m<n-2$. For Type I and II distributions, the $S_{f}$ distribution is truncated at $\sigma_{p}$; hence, $\sigma_{p}$ represents the minimum inert strength after proof testing. When flaw growth occurs on unloading (Type III distribution), the strength distribution is not truncated and no assurances of a minimum strength can be given. 
The experimental inert strength distributions after-proof testing could be divided generaliy into one of four distributions depending on the proof test conditions. First, under inert proof-test conditions (1iquid nitrogen) the strength distributions after proof testing agreed with that predicted from either a Type I, II, or III distribution (Fig. 1). In this case the Type II and III distributions were determined by assuming an $n=120 .^{6}$ As can be seen in Fig. 1 there was no significant difference between the three predicted distributions within the range of the after-proof data. This observation just reflects the fact that for an inert environment such as liquid nitrogen little or no crack growth can occur because of the high $n$ value appropriate for this environment.

Second, with rapid unloading rates in the dry nitogen and air environments, the strength distributions after proof testing agreed with that predicted from either a Type II or III distribution where $n=18.4^{8,9}$ (Fig. 2). Since the strength distributions after proof testing are shifted significantiy to the left of the Type I distribution, it is evident that crack growth occurs during proof testing in these "moist" environments; however, it could not be determined if the after-proof strength distributions were truncated at $\sigma_{p}$. To conclusively show truncation, much larger sample size after proof testing would have to be used (about 10000 samples).

Finaliy, when good proof-test controls were not used, i.e. relatively slow unloading rates and/or moist proof-test environments, the strength distributions after proof testing either were not different significantiy from the initial distribution (Fig. 3) or were weaker than the initial distribution (Fig. 4). In these cases none of the theoretical distributions could explain the observed distributions after proof testing since the strengths were much weaker than predicted from theory. 
Table I summarizes all the proof-test results. It is evident that for effective proof testing crack growth must be minimized through use of good proof test conditions, namely, rapid unloading rates and good environmental control. In addition, under experimental conditions where proof testing was not effective, ${ }^{+}$none of the theoretical, after-proof distributions agreed with the data. There was only one exception to these trends and that was for the proof test conducted in water at an unloading rate of $5.29 \mathrm{MPa} / \mathrm{s}$. It is not known why this one set of results did not fit into the general pattern.

To provide additional support to the general conclusions made above regarding the effectiveness of proof testing, a large group of asreceived microscope slides were proof tested in very dry nitrogen (less than $0.1 \%$ R.H.) and in moist nitrogen (50\% R.H.) using an unloading rate of about $13.2 \mathrm{MPa} / \mathrm{s}$. Because the dry nitrogen gas was a relatively inert environment, it was used as the test environment for the strength measurements before and after proof testing. Figure 5 and 6 shows that these results are in agreement with the trends shown in Table I. When good proof-test controls are used, proof testing is effective and the strength distribution after proof testing can be characterized theoretically (Fig. 5). On the other hand, when a relative slow unloading rate is used in a moist environment, proof testing is not effective in truncating the distribution and the after-proof strength distribution does not agree well with the theoretical distributions (Fig. 6).

The reader is cautioned not to jump to the conclusion that when good proof test controls are not used, proof testing will not be beneficial. It must be remembered that our conclusion is based on a group of uniformly abraded samples that could statistically be characterized by a single strength, i.e. flaw, distribution. If in a set of samples to be proof tested, some samples contain gross flaws, perhaps due to incorrect manufacturing, then proof testing even without ideal conditions, would undoubtedly eliminate these weak samples from the population, thereby, improving the reliability of the remaining samples. 
Based on the above proof test results, the question of why strengths after-proof testing under non-ideal conditions are significantly weaker than that predicted must be addressed. The use of Eq. (2) is a key assumption in deriving the strength after-proof testing. Experiments have characterized the dependence of crack velocity on stress intensity factor by three principal regions of behavior (Fig. 7). 10

Regions I and II result from a stress corrosion reaction between the glass and water in the environment. The rate of the reaction between water and the glass controls crack motion in Region I, whereas diffusion of water to the crack tip controls crack motion in Region II, where the crack velocity is essentially constant. In Region III the stress intensity factor is close to $K_{I C}$ and crack velocity does not depend on water in the environment. Since Eq. (2) represents Region I crack growth, the equations derived for the strength after-proof testing are based on the assumption that the strength is controlled exclusively by subcritical crack growth in Region I. If the behavior shown in figure 7 is important, then Eq. (2) would overestimate crack velocity when the stress intensity factor of the crack was in the range that characterizes region II, and the theory would predict failure when in fact, the samples may just pass the proof test. The samples that just survive the proof test would then be weak, and the distribution after the proof test would not be predicted from equation 3 or 4 . Therefore, an analysis that takes into account Region II crack growth is necessary to account for the observed strength distributions after proof testing under non-ideal conditions. An analysis of this sort is presented in Part II of this paper. 


\section{ACKNOWLEDGEMENTS}

Two of the authors (JER and PBO) are grateful for the support of the National Science Foundation Grant No. DMR 77-05647 for this research; the other (E..R. Fuller, Jr. and S. M. Wiederhorn) are greatful for the support of the Department of Energy, Fossil Fuel Utilization Division. 


\section{REFERENCES}

1. S.M. Wiederhorn, A.G. Evans and D.E. Roberts, "A Fracture Mechanics Study of the Skylab Windows," pp. 829-41 in Fracture Mechanics of Ceramics, Vol. 2, Edited by R.C. Bradt, D.P.H. Hasselman and F. F. Lange, Plenum Press, New York (1974).

2. S.M. Wiederhorn, A.G. Evans, E.R. Fuller and H. Johnson, "Application of Fracture Mechanics to Space-Shuttle Windows", J. Am. Ceram. Soc., 57, 319-23 (1974).

3. A.G. Evans, S.M. Wiederhorn, Melvin Linzer and E.R. Fuller, Jr., "Proof Testing of Procelain Insulators and Application of Acoustic Emission", Am. Ceram. Soc. Bu11., 54, 576-81 (1975).

4. J.E. Ritter, Jr. and S.A. Wulf, "An Evaluation of Proof Testing to ASsure Against Delayed Failure", to be published Am. Ceram. Soc. Bull. (1978).

5. A.G. Evans and S.M. Wiederhorn, "Proof Testing of Ceramic Materials An Analytical Basis for Failure Predictions", Int. J. Frac. Mech., 10, 379-92 (1974).

6. A.G. Evans and E.R. Fuller, "Proof Testing - The Effects of Slow Crack Growth", Mat. Sci. and Engr., 19, 69-77 (1975).

7. S.M. Wiederhorn, "Reliability, Life Prediction, and Proof Testing of Ceramics", pp 635-65 in Ceramics for High Performance Applications, Ed. by J. J. Burke, A.E. Gorum and R.N. Katz, Brook Hill Publishing Co., Chestnut Hi1l, MA. (1974).

8. J.E. Ritter, Jr., "Engineering Design and Fatigue Failure of Brittle Materials", pp 667-686 in Fracture Mechanics of Ceramics, Vol. 4, Edited by R.C. Bradt, D.P.H. Hasselman, and F.F. Lange, Plenum Publishing Co., New York (1978).

9. P.B. Dates, "A Detailed Study of the Proof-Test Technique for Assuring the Mechanical Reliability of Glass", M.S. Thesis in Mechanical Engineering, University of Massachusetts (1976).

10. S.M. Wiederhorn, "Influence of Water Vapor on Crack Propagation in Soda-Lime Glass", J. Am. Cera. Soc., 50, 407-14 (1967). 
Table I. Summary of the Proof-Test Data for Soda-Lime Silica Glass.

Proof-Test Environment

Liquid Nitrogen

Liquid Nitrogen

Dry Nitrogen Gas

Dry Nitrogen Gas

Dry Nitrogen Gas

Dry Nitrogen Gas

Air

Air

Air

Air

Water

Water

Water
Proof-Stress Unload Rate (MPa/s)

132.22

5.29

132.33

5.29

T. 32

5.29

132.33

5.29

1.32

5.29

132.33

5.29

5.29
Hold Time at Proof Stress (s)

$<0.5$

$<0.5$

$<0.5$

$<0.5$

$<0.5$

60

$<0.5$

$<0.5$

$<0.5$

5

$<0.5$

$<0.5$

5
After-Proof Inert Strength Distribution

I, II, III ${ }^{+}$

I, II, II I

II, III

Same as Initial

Same as Initial

Same as Initial

II, III

Weaker than Initial

Weaker than Initial

Same as Initial

Same as Initial

II, II I

Same as Initial

+Type theoretical distributions that agreed with after-proof data. 
Fig. 1. Inert strength distributions of soda-lime-silicate glass before and after proof testing compared to the theoretical, after-proof distributions. Proof testing was in liquid nitrogen at unload ràte of $5.29 \mathrm{MPa} / \mathrm{s}$ and $\sigma_{p}=127.5 \mathrm{MPa}, F_{p}=0.36, n=120$, $m=8.19, S_{0}=137.4 \mathrm{MPa}$.

Fig. 2. Inert strength distributions of soda-1ime-silicate glass before and after proof testing compared to the theoretical, after-proof distributions. Proof testing was in air at unload rate of 132.3 $\mathrm{MPa} / \mathrm{s}$ and $\sigma_{p}=79.3 \mathrm{MPa}, \mathrm{F}_{p}=0.33, n=18.4, \mathrm{~m}=8.19$, $S_{0}=137.4 \mathrm{MPa}$.

Fig. 3. Inert strength distributions of soda-lime silicate glass before and after proof testing compared to the theoretical, after-proof distributions. Proof testing was in water at unload rate of 132.3 $\mathrm{MPa} / \mathrm{s}$ and $\sigma_{p}=68.6 \mathrm{MPa}, F_{p}=0.37, n=18.4, m=8.19, \mathrm{~S}_{0}=137.4 \mathrm{MPa}$.

Fig. 4. Inert strength distributions of soda-lime silicate glass before and after proof testing compared to the theoretical, after-proof distributions. Proof testing was in air at unload rate of $5.29 \mathrm{MPa} / \mathrm{s}$ and $\sigma_{p}=79.3 \mathrm{MPa}, F_{p}=0.47, n=18.4, m=8.19, S_{0}=137.4 \mathrm{MPa}$.

Fig. 5. Strength distributions for soda-lime-silicate glass in very dry nitrogen gas before and after proof testing compared to the theoretical, after-proof distributions. Proof testing was in very dry nitrogen gas at unload rate of $13.2 \mathrm{MPa} / \mathrm{s}$ and $\sigma_{p}=103.9 \mathrm{MPa}$, $F_{p}=0.30$, and $n=120$. 
Fig. 6. Strength distributions for soda-lime-silicate glass in very dry nitrogen gas before and after proof testing compared to the theoretical, after-proof distributions. Proof testing was in $50 \%$ R.H. nitrogen gas at unload rate of $13.2 \mathrm{MPa} / \mathrm{s}$ and $\sigma_{p}=103.9 \mathrm{MPa}$, $F_{p}=0.58$, and $n=18.4$.

Fig. 7. Crack propagation behavior of soda-lime-silicate glass in moist nitrogen gas environments. Percent relative humidity is given on the right hand side of diagram (after Wiederhorn, reference 10). 


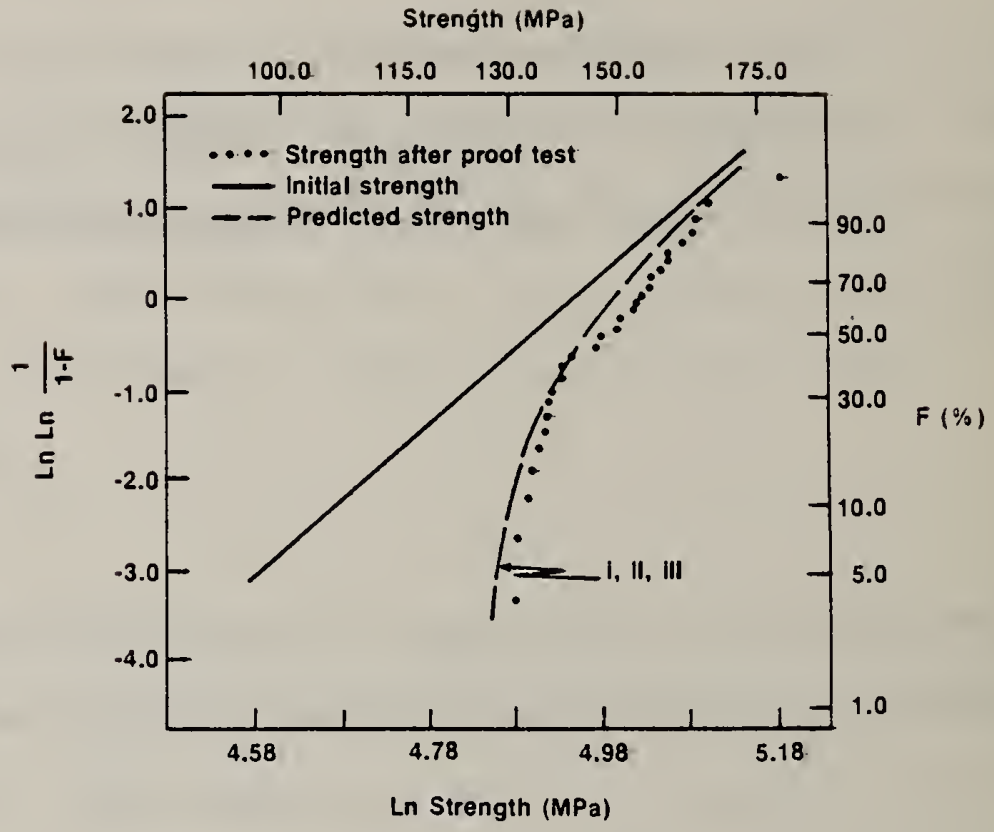

Fig. 1. Inert strength distributions of soda-lime-silicate glass before and after proof testing compared to the theoretical, after-proof distributions. Proof testing was in liquid nitrogen at unload rate of $5.29 \mathrm{MPa} / \mathrm{s}$ and $\sigma_{p}=127.5 \mathrm{MPa}, F_{p}=0.36, n=120$, $m=8.19, S_{0}=137.4 \mathrm{MPa}$. 


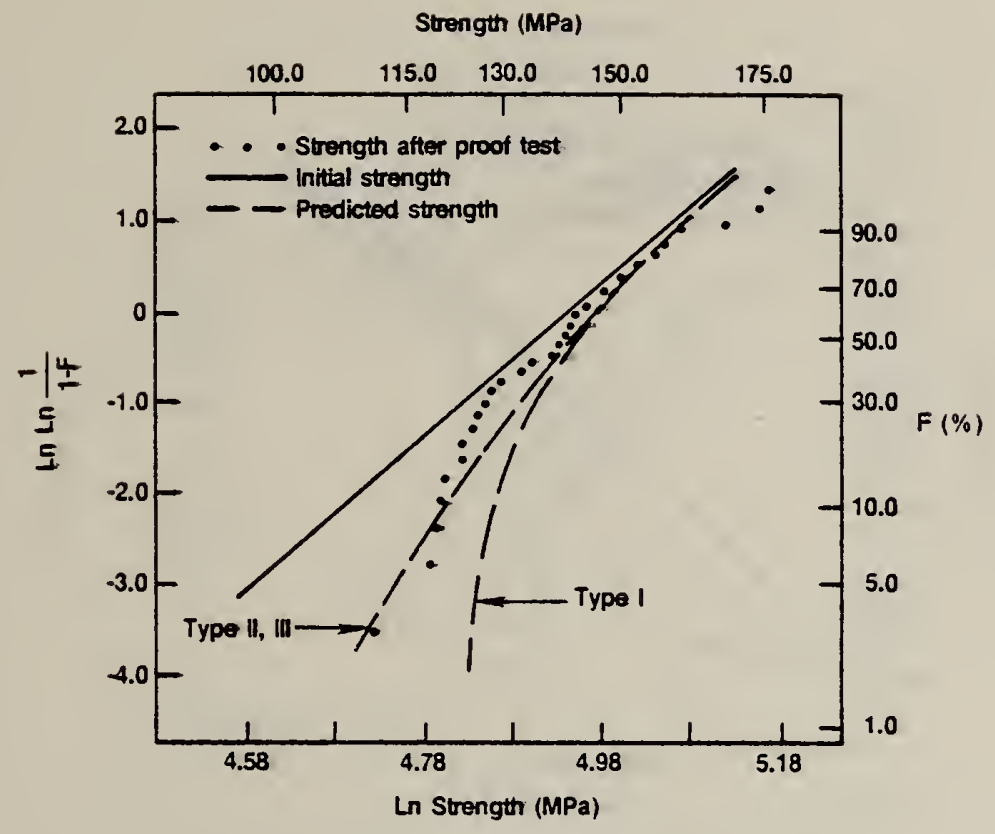

=ig. 2. Inert strength distributions of soda-lime-silicate glass before and after proof testing compared to the theoretical, after-proof distriblitions. Proof testing was in air at unload rate of 132.3 $\mathrm{MPa} / \mathrm{s}$ and $\sigma_{p}=79.3 \mathrm{MPa}, F_{p}=0.33, n=18.4, \mathrm{~m}=8.19$, $S_{0}=137.4 \mathrm{MPa}$. 


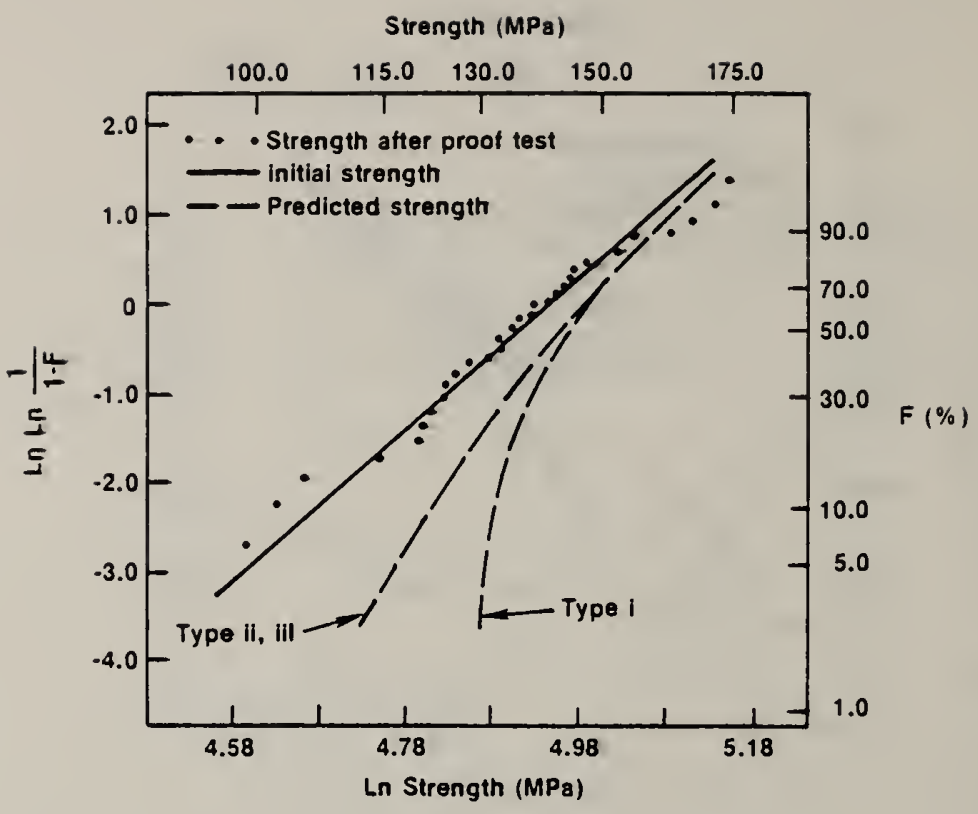

Fig. 3. Inert strength distributions of soda-lime silicate glass before and after proof testing compared to the theoretical, after-proof distributions. Proof testing was in water at unioad rate of 132.3 $\mathrm{MPa} / \mathrm{s}$ and $\sigma_{p}=68.6 \mathrm{MPa}, F_{p}=0.37, n=18.4, m=8.19, \mathrm{~S}_{0}=137.4 \mathrm{MPa}$. 


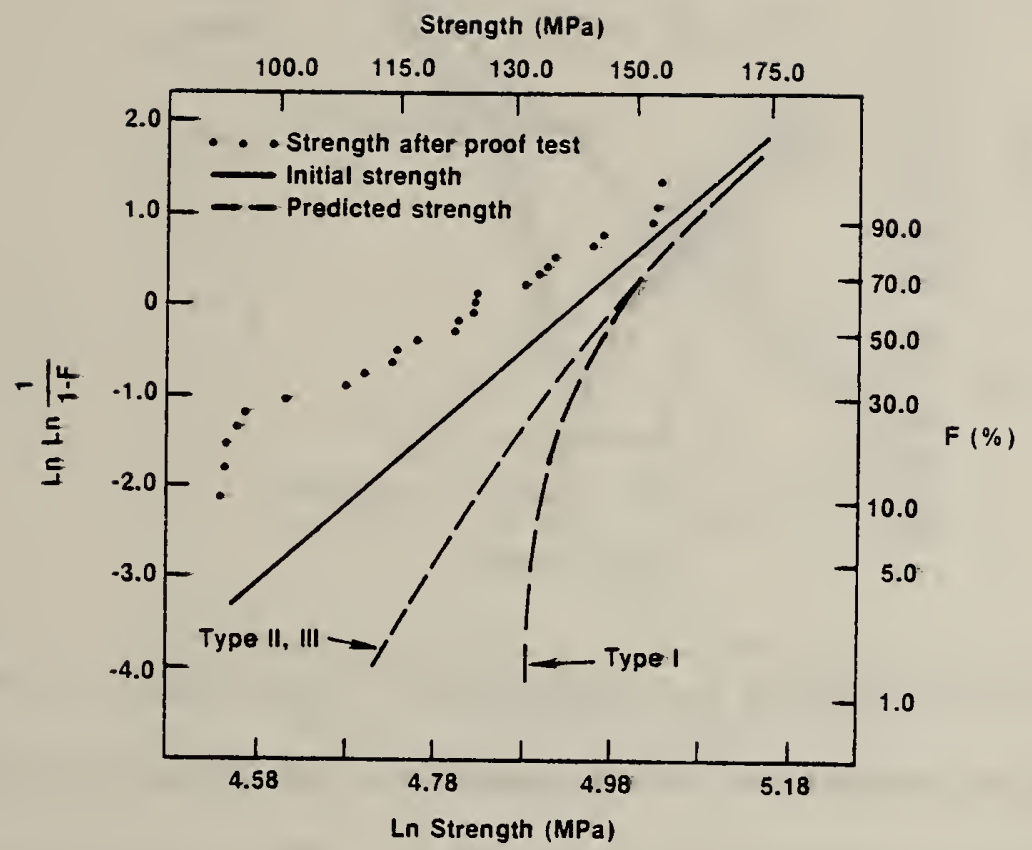

Fig. 4. Inert strength distributions of soda-lime silicate glass before and after proof testing compared to the theoretical, after-proof distributions. Proof testing was in air at unload rate of $5.29 \mathrm{MPa} / \mathrm{s}$ and $\sigma_{p}=79.3 \mathrm{MPa}, F_{p}=0.47, n=18.4, m=8.19, s_{0}=137.4 \mathrm{MPa}$. 


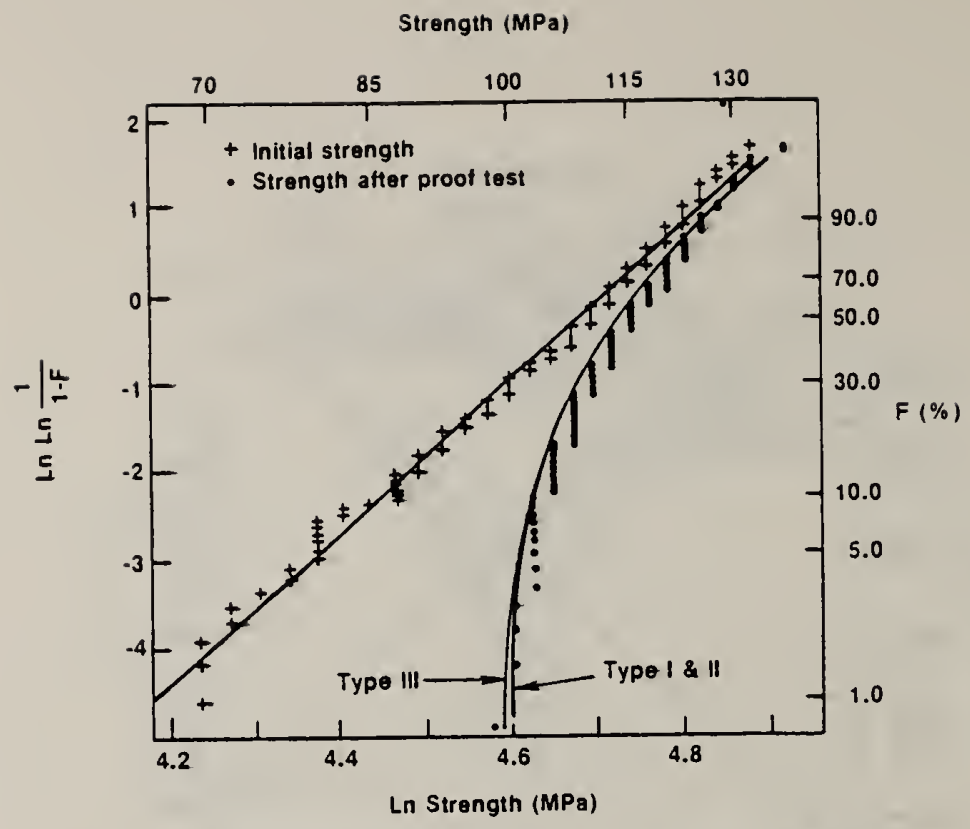

Fig. 5. Strength distributions for soda-lime-siticate glass in very dry nitrogen gas before and after proof testing compared to the theoretical, after-proof distributions. Proof testing was in very dry nitrogen gas at unload rate of $13.2 \mathrm{MPa} / \mathrm{s}$ and $\sigma_{p}=103.9 \mathrm{MPa}$, $F_{p}=0.30$, and $n=120$. 


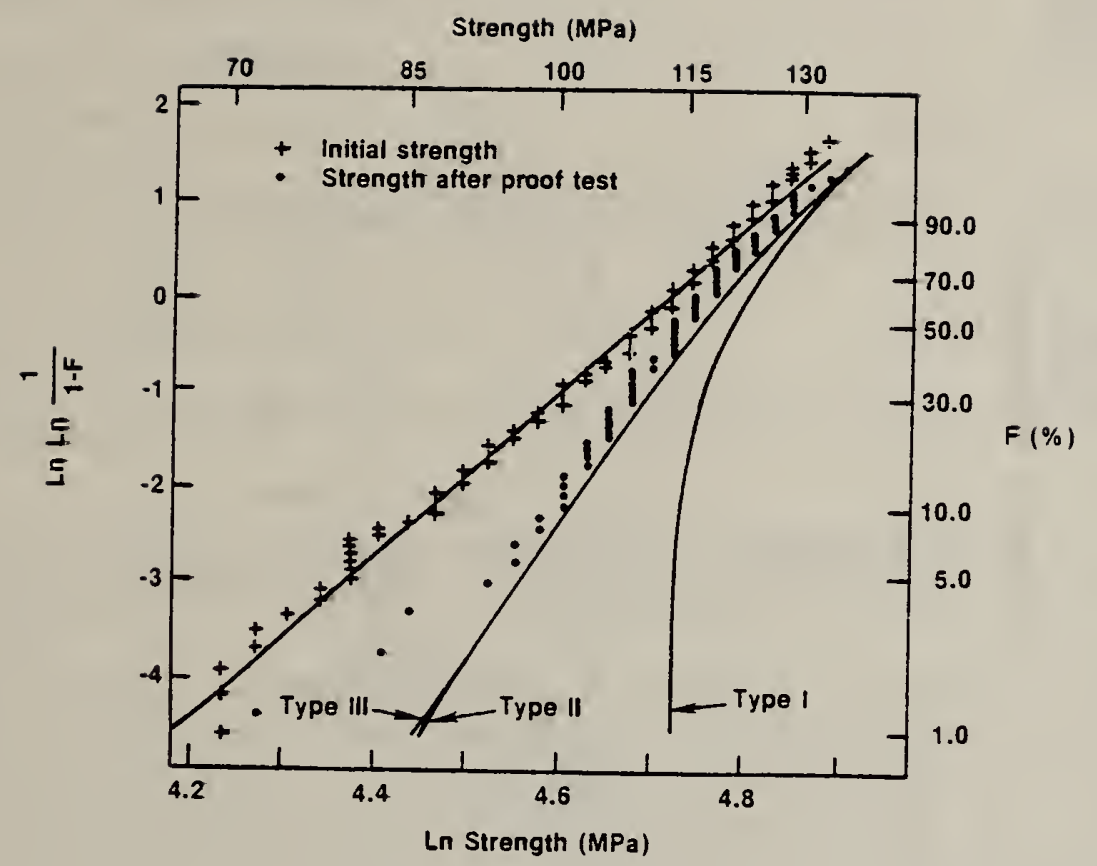

ig. 6. Strength distributions for soda-lime-silicate glass in very dry nitrogen gas before and after proof testing compared to the theoretical, after-proof distributions. Proof testing was in $50 \%$ R.H. nitrogen gas at unload rate of $13.2 \mathrm{MPa} / \mathrm{s}$ and $\sigma_{p}=103.9 \mathrm{MPa}$, $F_{p}=0.58$, and $n=18.4$. 


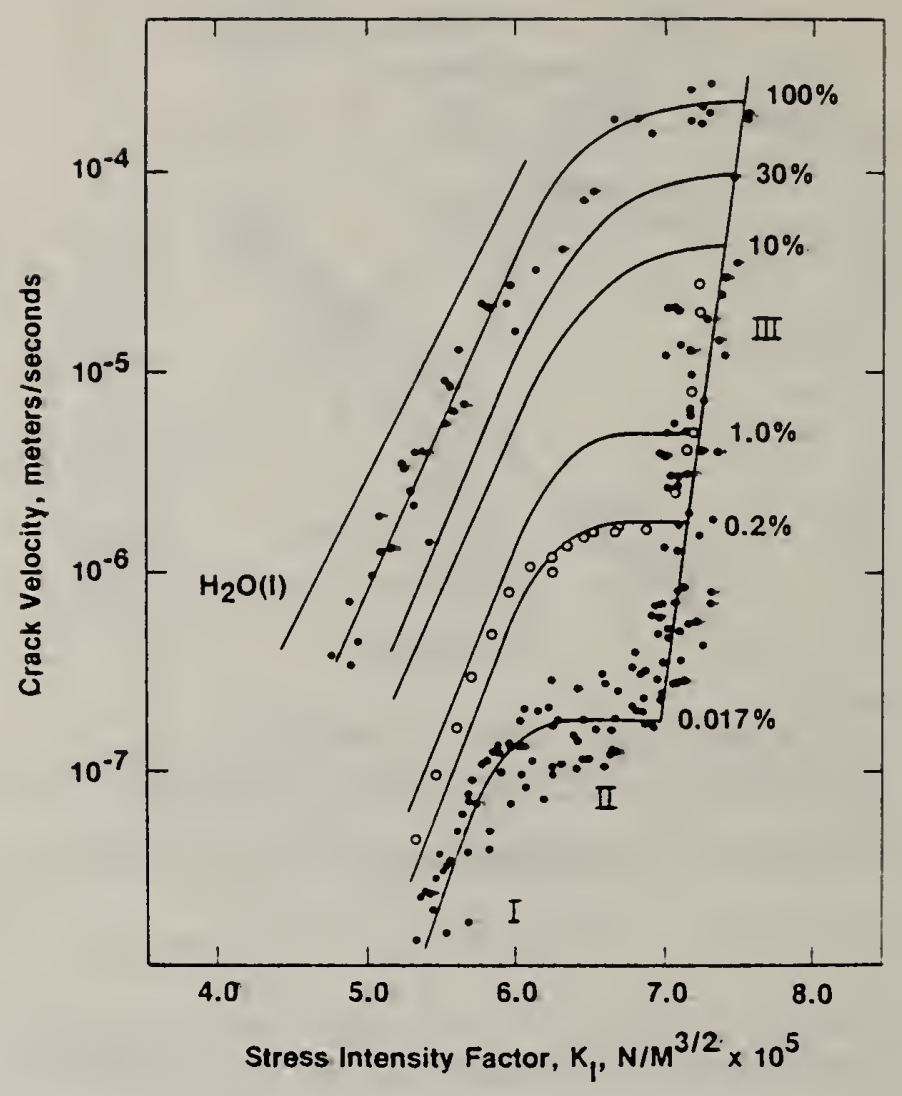

Fig. 7. Crack propagation behavior of soda-lime-silicate glass in moist nitrogen gas environments. Percent relative humidity is given on the right hand side of diagram (after Wiederhorn, reference 10). 
NBS-114A (REV. 9-78)

U.S. DEPT. OF COMM

BIBLIOGRAPHIC DATA SHEET

1. PUBLICATION OR REPORT NO.

79-1934

4. TITLE AND SUBTITLE

Proof Testing of Ceramics: I. Experiment

7. AUTHOR(S)

J. E. Ritter, Jr., P. B. Oates, E. R. Fuller, Jr.

and S. M. Wiederhorn

9. PERFORMING ORGANIZATION NAME AND ADDRESS

NATIONAL BUREAU OF STANDARDS

DEPARTMENT OF COMMERCE

WASHINGTON, DC 20234

12. SPONSORING ORGANIZATION NAME AND COMPLETE ADDRESS (Street, City, State, zIP)

Department of Energy

Fossil Fuel Utilization Division

Washington, D. C.

2. Gon Accession Na.18

5. Publication Date

/.

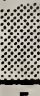

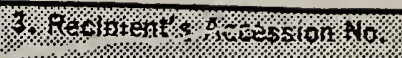

6. Performing Organization Code

8. Performing Organ. Report No.

5. SUPPLEMENTARY NOTES

Document describes a computer program; SF-185, FIPS Software Summary, is attached.

16. ABSTRACT (A 200-word or less factual summary of most significant information. If document includes a significant bibliography or literature survey, mention it here.)

The effectiveness of proof testing as a method of improving component reliability was studied by comparing the inert strength distributions of soda-lime-silicate glass before and after proof testing. The effects of unloading rate from the proof stress, hold time at the proof stress, and proof-test environment were examined. The results indicate that the proof test must be conducted with rapid unloading rates and good environmental control to be effective. The theoretical implications of these results are discussed.

17. KEY WORDS (six to twelve entries; alphabetical order; capitalize only the first letter of the first key word unless a proper name; separated by semicolons)

Ceramics; crack growth; fracture; glass; proof testing; strength

For Official Distribution. Do ilot Release to NTIS

Order From Sup. of Doc., U.S. Government Printing Office, Washington, DC 20402, SD Stock No. SNO03-003-

[.] Order From National Technical Information Service (NTIS), Springfield, VA. 22161

\begin{tabular}{|l|c|}
\hline $\begin{array}{l}\text { 19. SECURITY CLASS } \\
\text { (THIS REPORT) }\end{array}$ & $\begin{array}{c}\text { 21. NO. OF } \\
\text { PRINTED PAGES } \\
\text { UNCLASSIFIED }\end{array}$ \\
\hline $\begin{array}{l}\text { 20. SECURITY CLASS } \\
\text { (THIS PAGE) }\end{array}$ & 22. Price \\
UNCLASSIFIED & $\$ 4.00$ \\
\hline
\end{tabular}


